Комплексный анализ ассортимента серотонинергических средств и субстанций для их производства, зарегистрированных в России

\author{
Нягматуллина В.Р. ${ }^{1}$ Егорова С.Н.. ${ }^{2}$ Чувашова Д.П. ${ }^{1}$, Филиппов Ю.В. ${ }^{1}$
}

${ }^{1} \mathrm{AO}$ «Татхимфармпрепараты» (Казань)

${ }^{2}$ ФББОУ ВО «Казанский государственный медицинский университет» Минздрава России, Институт фармации

\title{
Comprehensive analysis of the range of serotonergic agents and substances for their production registered in Russia
}

\author{
Niagmatullina V.R. ${ }^{1}$, Egorova S.N. ${ }^{2}$, Chuvashova D.P. ${ }^{1}$, Filippov Yu.V. ${ }^{1}$ \\ ${ }^{1} J S C$ "Tatchempharmpreparaty” (Kazan) \\ ${ }^{2}$ Kazan State Medical University, Institute of Pharmacy
}

\begin{abstract}
АННОТАЦИЯ
В статье представлена характеристика серотонинергических лекарственных средств (механизм действия, классификация, фармакодинамические и фармакокинетические свойства, лекарственные взаимодействия с препаратами других фармакологических групп). Проанализирован отечественный фармацевтический рынок лекарственных препаратов (ЛП) серотонинергических средств и субстанций для их производства, зарегистрированных в Российской Федерации (РФ).

Установлено, что фармацевтический рынок серотонинергических средств в РФ достаточно разнообразен. Представлены ЛП различных фармакологических групп (анксиолитики, противорвотные, сосудорасширяющие и улучшающие периферическое кровообращение, слабительные, гемостатики и противомигренозные средства) в различных лекарственных формах (таблетки - 5.71 \%; таблетки, покрытые пленочной оболочкой - 41.43 \%; инъекционный раствор для внутривенного и внутримышечного применения - 34.28 \%; концентрат для приготовления раствора для инфузий -8.57 \%; растворы для внутривенного введения и суппозитории ректальные - по 2.86 \% с сироп, таблетки лиофилизированные и капсулы - по 1.43 \%). Лидирующая роль на российском фармацевтическом рынке принадлежит отечественным производителям ЛП серотонинергических средств (59.70 \%), которые в основном представлены воспроизведенными препаратами. Зарубежным производителям принадлежит 40.30 \% рынка ЛП серотонинергических средств, причем лидирующие позиции занимают производители Индии (8.96 \%), Швейцарии (5.97\%), Израиля (4.48 \%). Анализ ассортимента фармацевтических субстанций для производства серотонинергических средств показал, что на российском фармацевтическом рынке преобладают зарубежные производители (52.38 \%). На долю отечественных поставщиков приходится 47.62 \% производителей субстанций, зарегистрированных в Российской Федерации.
\end{abstract}

\section{Ключевъе слова: серотонинергические средства, фармацевтический рынок.}

\begin{abstract}
The article presents the characteristics of serotonergic drugs (mode of action, classification, pharmacodynamic and pharmacokinetic properties, drug interactions with medicinal products of other pharmacological groups). The domestic pharmaceutical market of serotonergic drug products (DP) and substances for their production registered in the Russian Federation (RF) was analyzed.

It was established that the pharmaceutical market of serotonergic agents in the RF is quite diverse. Various pharmacological groups of drugs (anxiolytic, antiemetic, vasodilatory and peripheral circulation improving, evacuant, hemo-

Поступила 13.11.2020

Принята 24.12.2020

Автор, ответственный за переписку

Егорова Светлана Николаевна: ФГБОУ ВО «Казанский государственный медицинский университет» Минздрава России, Институт фармации. 420012, г. Казань, ул. Бутлерова, 49. E-mail: svetlana.egorova@kazangmu.ru

Received 13.11.2020

Accepted 24.12.2020

Corresponding author

Egorova Svetlana Nikolayevna: Kazan State Medical University, Institute of Pharmacy, 49, Butlerova str., Kazan, 420012, Russia.

E-mail: svetlana.egorova@kazangmu.ru
\end{abstract}


static and anti-migraine agents) are presented in various dosage forms (tablets $-5.71 \%$; film-coated tablets $-41.43 \%$; injectable solution for intravenous and intramuscular use $-34.28 \%$; concentrate for preparation of solution for injections - 8.57\%; solutions for intravenous administration and rectal suppositories - by $2.86 \%$; syrup, freeze-dried tablets and capsules - by 1.43\%). The leading role in the Russian pharmaceutical market belongs to domestic manufacturers of serotonergic DP (59.70\%), which are mainly presented by generic drugs. Foreign manufacturers own $40.30 \%$ of the market for serotonergic DP, with the leading positions held by manufacturers of India (8.96\%), Switzerland (5.97\%), Israel (4.48\%). The analysis of the range of pharmaceutical substances for the production of serotonergic DP showed that the Russian pharmaceutical market is dominated by foreign manufacturers (52.38\%). The proportion of domestic providers accounts for $47.62 \%$ of the manufacturers of substances registered in the Russian Federation.

Keywords: serotonergic agents, pharmaceutical market.

\section{$\mathbb{B B E} \mathbb{B} H И \mathbb{E}$}

К группе серотонинергических средств относятся лекарственные препараты (ЛП), взаимодействующие со специфическими серотониновыми, или 5-НТ (5-гидрокситриптаминовыми), рецепторами. Вследствие разнообразия серотониновых рецепторов химическое строение и фармакологические свойства ЛП данной группы также многообразны.

На фармацевтическом рынке ЛП серотонинергических средств представлены в твердых, мягких и жидких лекарственных формах (ЛФ) различных дозировок и концентраций. Появление новых фармацевтических субстанций, разработка отечественными фармацевтическими предприятиями новых ЛП в ЛФ, востребованных здравоохранением, при уже имеющемся широком ассортименте готовых лекарственных средств данной группы обусловливают необходимость в систематизации имеющихся данных об ассортименте и основных фармакологических свойствах серотонинергических ЛП.

\section{ЦЕЛЬ ИССЛЕДОВАНИЯ}

Анализ ассортимента серотонинергических лекарственных средств и субстанций для их производства, зарегистрированных в Российской Федерации, а также систематизация данных о механизме их действия, фармакологических эффектах и лекарственных взаимодействиях.

\section{МЕТОДЫ ИССЛЕДОВАНИЯ}

Логический, статистический, структурный, контент-анализ. Объекты исследования: Государственный реестр лекарственных средств (ГРЛС) России, научные издания и ресурсы сети Internet.

\section{РЕЗУЛЬТАТЫ И ОБСУЯКДЕНИЕ}

Серотонин содержится почти во всех органах и тканях, однако его большая часть (более 90 \%) обнаруживается в энтерохромаффинных клетках желудочно-кишечного тракта (ЖКТ). В кровь серо-

\section{INTRODUCTION}

The group of serotonergic agents includes drug products (DP) that interact with specific serotonin, or 5-HT (5-hydroxytryptamine), receptors. Due to the variety of serotonin receptors, the chemical structure and pharmacological properties of this group of drugs are also diverse.

In the pharmaceutical market, serotonergic agents are available in solid, soft and liquid dosage forms (DF) of various dosages and concentrations. The emergence of new pharmaceutical substances, the development by domestic pharmaceutical enterprises of new drugs in DF, which are in demand by the healthcare sector, with the already existing wide range of finished pharmaceutical products of this group, make it necessary to systematize the available data on the range and main pharmacological properties of serotonergic DP.

\section{AIM OF THE RESEARCH}

Analysis of the range of serotonergic agents and substances for their production registered in the Russian Federation, as well as systematization of data on the mechanism of their action, pharmacological effects and drug interactions.

\section{METHODS OF THE RESEARCH}

Logical, statistical, structural, and content analysis. Objects of research: State Register of Medicinal Remedies (SRMR) of Russia, scientific publications and Internet resources.

\section{RESULTS AND DISCUSSION}

In essence all organs and tissues contain serotonin, but most of it (more than 90\%) is found in enterochromaffin cells of the gastrointestinal tract (GI). Serotonin enters the blood through active transport and accumulates in platelets, in the central nervous system - in serotonergic neurons that synthesize and secrete it [1]. The pharmaco- 
тонин поступает посредством активного транспорта и накапливается в тромбоцитах, в центральной нервной системе - в серотонинергических нейронах, которые синтезируют и выделяют его [1]. Фармакологические эффекты серотонина реализуются через возбуждение серотониновых рецепторов типов 5-НТ1, 5-НТ2 и 5-НТ3. Его основное действие проявляется вазоконстрикцией (кроме сосудов скелетных мышц и сердца), сокращением гладких мышц, повышением артериального давления, активацией агрегации тромбоцитов, усилением тонуса и перистальтики ЖКТ, стимуляцией боли и развитием приступов тошноты и рвоты.

По механизму действия все серотонинергические средства делятся на агонисты и антагонисты серотониновых рецепторов. К агонистам серотониновых рецепторов относятся буспирон, золмитриптан, ондансетрон, прукалоприд, серотонин, суматриптан и элетриптан, а к антагонистам - гранисетрон, нафтидрофурил, палоносетрон и трописетрон.

В основном серотонинергические средства представлены ЛП, оказывающими противомигренозное и противорвотное действие. К противомигренозным ЛП относятся суматриптан, золмитриптан, избирательно стимулирующий 5-HT1D- и 5-HT1B-рецепторы, и элетриптан, используемый для купирования приступов мигрени с аурой и без [2]. Противорвотные препараты - гранисетрон, ондансетрон, палоносетрон, трописетрон - применяются с целью профилактики и лечения тошноты и рвоты, вызванных цитостатической химиотерапией и лучевой терапией, а также в послеоперационный период. Агонисты 5-НТ1А-рецепторов являются представителями нового класса транквилизаторов - азапиронов, в число которых входит буспирон [3]. Разработаны ЛП серотонинергических средств с сосудорасширяющим и улучшающим периферическое кровообращение (нафтидрофурил) и со слабительным (прукалоприд) действием [4]. Принадлежность серотонинергических средств к группам по анатомо-терапевтическо-химической (ATX) классификации представлена в табл. 1.

Побочные действия серотонинергических средств, обычно слабовыраженные или умеренные, носят преходящий характер. В основном они проявляются в виде головной боли, головокружения [5, 6], нарушений сна (бессонницы или сонливости), со стороны ЖКТ - тошноты, запора, диареи, боли в эпигастрии $[7,8]$. Возможно также появление кожной сыпи, покраснения и зуда [4]. Клинически важные побочные эффекты отсутствуют [9]. logical effects of serotonin are realized through the stimulation of serotonin receptors of types 5 - $\mathrm{HT} 1,5-\mathrm{HT} 2$ and $5-\mathrm{HT}_{3}$. Its main action is manifested by vasoconstriction (except for the vessels of skeletal muscles and the heart), contraction of smooth muscles, high blood pressure, activation of platelet aggregation, increased tonicity and peristalsis of the GI, stimulation of pain and the development of nausea and vomiting.

According to the mechanism of action, all serotonergic agents are divided into agonists and antagonists of serotonin receptors. Serotonin receptor agonists include buspirone, zolmitriptan, ondansetron, prucalopride, serotonin, sumatriptan, and eletriptan, while antagonists include granisetron, naftidrofuril, palonosetron, and tropisetron.

Serotonergic agents are mainly represented by DP that have anti-migraine and antiemetic effects. Anti-migraine drugs include sumatriptan, zolmitriptan, which selectively stimulates the 5-HT1D and $5-\mathrm{HT} 1 \mathrm{~B}$ receptors, and eletriptan, which is used to relieve migraine attacks with and without aura [2]. Antiemetic drugs (granisetron, ondansetron, palonosetron, tropisetron) are used to prevent and treat nausea and vomiting caused by cytostatic chemotherapy and radiation therapy, as well as in the postoperative period. The 5-HT1A-receptor agonists are representatives of a new class of tranquilizers - azapirons, which include buspirone [3]. Serotonergic DP with vasorelaxant, and improving peripheral blood circulation (naftidrofyrul), and with a laxative (prucalopride) effect have been developed [4]. The affiliation of serotonergic agents to the groups according to the Anatomical Therapeutic Chemical Classification System (ATC) is presented in Table 1.

Side effects of serotonergic drugs, usually mild or moderate, are transient. They are mainly manifested in the form of headache, dizziness [5, 6], sleep disorders (insomnia or drowsiness), gastrointestinal disorders, such as nausea, constipation, diarrhea, epigastric pain $[7,8]$. Skin rashes, redness, and itching may also occur [4]. There are no clinically important side effects [9].

Concomitant use of serotonergic agents with MAO-A inhibitors (for example, with moclobemide) [3], selective serotonin reuptake inhibitors and selective serotonin and noradrenaline reuptake inhibitors [10], and other serotonergic agents can lead to the development of serotonin syndrome including changes in mental state, autonomic dysfunction, 
Таблица 1. Группы серотонинергических средств по АТХ-классификации

Table 1. Groups of serotonergic agents according to the ATC

\begin{tabular}{|c|c|c|}
\hline $\begin{array}{l}\text { Международное непатентованное } \\
\text { наименование (MHH) / } \\
\text { International non-proprietary name (INN) }\end{array}$ & Группа ATX / ATC group & $\begin{array}{l}\text { Код ATX } \\
\text { ATC code }\end{array}$ \\
\hline $\begin{array}{l}\text { Буспирон (Buspironum) } \\
\text { Buspirone (Buspironum) }\end{array}$ & $\begin{array}{l}\text { Производные азаспиродекандиона } \\
\text { Azaspyrodecanedione derivatives }\end{array}$ & No5BE01 \\
\hline $\begin{array}{l}\text { Гранисетрон (Granisetronum) } \\
\text { Granisetron (Granisetronum) }\end{array}$ & $\begin{array}{l}\text { Противорвотные препараты. Блокаторы серотониновых } \\
\text { 5-НT1-рецепторов } \\
\text { Antiemetic agents. 5-HT1 receptor antagonists }\end{array}$ & A04AA02 \\
\hline $\begin{array}{l}\text { Золмитриптан (Zolmitriptanum) } \\
\text { Zolmitriptan (Zolmitriptanum) }\end{array}$ & $\begin{array}{l}\text { Селективные агонисты серотониновых 5-НТ1-рецепторов } \\
\text { Selective 5-HT1 receptor agonists }\end{array}$ & $\mathrm{No} 2 \mathrm{CCO} 3$ \\
\hline $\begin{array}{l}\text { Нафтидрофурил (Naftidrofurylum) } \\
\text { Naftidrofuryl (Naftidrofurylum) }\end{array}$ & $\begin{array}{l}\text { Прочие периферические вазодилататоры } \\
\text { Other peripheral vasodilators }\end{array}$ & Co4AX21 \\
\hline $\begin{array}{l}\text { Ондансетрон (Ondansetronum) } \\
\text { Ondansetron (Ondansetronum) }\end{array}$ & $\begin{array}{l}\text { Антагонисты серотонина } \\
\text { Serotonin antagonists }\end{array}$ & A04AA01 \\
\hline $\begin{array}{l}\text { Палоносетрон (Palonosetronum) } \\
\text { Palonosetron (Palonosetronum) }\end{array}$ & $\begin{array}{l}\text { Антагонисты серотонина } \\
\text { Serotonin antagonists }\end{array}$ & A04AA05 \\
\hline $\begin{array}{l}\text { Прукалоприд (Prucalopridum) } \\
\text { Prucalopride (Prucalopridum) }\end{array}$ & $\begin{array}{l}\text { Прочие слабительные } \\
\text { Other laxatives }\end{array}$ & Ao6AXo5 \\
\hline $\begin{array}{l}\text { Серотонин (Serotoninum) } \\
\text { Serotonin (Serotoninum) }\end{array}$ & $\begin{array}{l}\text { Стимуляторы моторики желудочно-кишечного тракта } \\
\text { Promotility agents }\end{array}$ & Ao3FA \\
\hline $\begin{array}{l}\text { Суматриптан (Sumatriptanum) } \\
\text { Sumatriptan (Sumatriptanum) }\end{array}$ & $\begin{array}{l}\text { Селективные агонисты серотониновых 5-НТ1-рецепторов } \\
\text { Selective 5-HT1 receptor agonists }\end{array}$ & No2CCo1 \\
\hline $\begin{array}{l}\text { Трописетрон (Tropisetronum) } \\
\text { Tropisetron (Tropisetronum) }\end{array}$ & $\begin{array}{l}\text { Антагонисты серотонина } \\
\text { Serotonin antagonists }\end{array}$ & A04AA03 \\
\hline $\begin{array}{l}\text { Элетриптан (Eletriptanum) } \\
\text { Eletriptan (Eletriptanum) }\end{array}$ & $\begin{array}{l}\text { Селективные агонисты серотониновых 5-НТ1-рецепторов } \\
\text { Selective 5-HT1 receptor agonists }\end{array}$ & No2CCo6 \\
\hline
\end{tabular}

Одновременное применение ЛП серотонинергических средств с ингибиторами МАО-А (например, с моклобемидом) [3], селективными ингибиторами обратного захвата серотонина и селективными ингибиторами обратного захвата серотонина и норадреналина [10] и другими серотонинергическими лекарственными средствами может приводить к развитию серотонинового синдрома, включающего изменение психического состояния, вегетативную дисфункцию и нарушения со стороны нервной и мышечной систем. Особенно такое лекарственное взаимодействие характерно для триптанов (суматриптан, золмитриптан, элетриптан), используемых для лечения и профилактики приступов мигрени; для противорвотных средств (ондансетрон, палоносетрон, гранисетрон) и для анксиолитика буспирона. Триптаны также не используют совместно с нитратами и бета-адреноблокаторами у пациентов с ишемической болезнью сердца и с алкалоидами спорыньи в связи с риском возникновения коронароспазма. С осторожностью следует принимать ЛП агонистов серотониновых рецепторов в комбинациях с ингибиторами и индукторами and disorders of the nervous and muscular systems. This drug interaction is especially characteristic of triptans (sumatriptan, zolmitriptan, eletriptan) used for the treatment and prevention of migraine attacks; of antiemetics (ondansetron, palonosetron, granisetron) and an ataractic drug buspirone. Triptans are also not used in conjunction with nitrates and beta-blockers in patients with coronary heart disease, just as ergot alkaloids due to the risk of coronary spasm. DP of serotonin receptor agonists should be taken with caution in combination with inhibitors and inducers of $\mathrm{CYP}_{3} \mathrm{~A}_{4}, \mathrm{CYP} 1 \mathrm{~A} 2, \mathrm{CY}-$ P2D6 and other microsomal liver enzymes, as well as with barbiturates and tricyclic antidepressants due to changes in the level of the serotonin receptor agonist in blood plasma and its pharmacological effects [4].

The main characteristics of the pharmacological action and side effects of serotonergic DP are presented in Table 2.

Currently, 11 international non-proprietary names of serotonergic agents under 70 trade names (TN) in various DP are registered in the 
Таблица 2. Фармакологическое действие и побочные эффекты серотонинергических средств [4]

Table 2. Pharmacological action and side effects of serotonergic agents [4]

\begin{tabular}{|c|c|c|}
\hline $\begin{array}{l}\text { MHH } \\
\text { INN }\end{array}$ & $\begin{array}{l}\text { Фармакологическое } \\
\text { действие } \\
\text { Pharmacological action }\end{array}$ & $\begin{array}{l}\text { Частые побочные эффекты } \\
\text { Common side effects }\end{array}$ \\
\hline $\begin{array}{l}\text { Буспирон } \\
\text { (Buspironum) } \\
\text { Buspirone } \\
\text { (Buspironum) }\end{array}$ & Анксиолитическое & $\begin{array}{l}\text { Головокружение, головная боль, слабость, нарушение сна, снижение внимания [3] } \\
\text { Боль в груди, шум в ушах, ларингит, отек слизистой носа } \\
\text { Dizziness, headache, weakness, sleep disturbance, poor attention [3] } \\
\text { Chest pain, tinnitus, laryngitis, swelling of the nasal mucosa }\end{array}$ \\
\hline $\begin{array}{l}\text { Гранисетрон } \\
\text { (Granisetronum) } \\
\text { Granisetron }\end{array}$ & $\begin{array}{l}\text { Противорвотное } \\
\text { Antiemetic }\end{array}$ & $\begin{array}{l}\text { Головная боль, головокружение [9] } \\
\text { Headache, dizziness [9] }\end{array}$ \\
\hline
\end{tabular}

(Granisetronum)

Золмитриптан

(Zolmitriptanum)

Zolmitriptan

(Zolmitriptanum)

Противомигренозное Головная боль, головокружение, нарушение сна, тошнота, рвота, боль в эпигастрии, кишечная колика, язвы слизистой оболочки желудка, аллергические реакции, диарея, снижение аппетита, обратимое повышение уровня печеночных ферментов Headache, dizziness, sleep disturbance, nausea, vomiting, epigastric pain, enterodynia, stomach ulcers, allergic reactions, diarrhea, loss of appetite, a reversible increase in liver enzymes

Нафтидрофурил (Naftidrofurylum)

Naftidrofuryl

(Naftidrofurylum)

Сосудорасширяющее, Тошнота, боль в эпигастрии, крапивница, зуд, гепатит, печеночная

улучшающее периферическое

кровообращение Vasodilating, improving peripheral

blood circulation недостаточность, повышение активности печеночных трансаминаз (АлТ, АсТ) [8], запор или диарея, аритмия, боль в груди, метеоризм, диспепсия, головная боль, бессонница, сонливость, чрезмерная утомляемость или слабость, снижение или повышение АД, кожная сыпь, гипертермия, бронхоспазм

Nausea, epigastric pain, urticaria, itching, hepatitis, liver failure, an increase in activity of hepatic transaminases (ALAT, AspAT) [8], constipation or diarrhea, arrhythmia, chest pain, flatulence, dyspepsia, headache, insomnia, drowsiness, excessive fatigue or weakness, a decrease or increase of blood pressure, skin rash, hyperthermia, bronchial spasm

\begin{tabular}{ll}
\hline Ондансетрон & Противорвотное \\
(Ondansetronum) & Antiemetic \\
Ondansetron & \\
(Ondansetronum) &
\end{tabular}

Головная боль, головокружение, диарея [5], чувство жара или приливы, запор, местные реакции (жжение в месте инъекции; ощущение жжения в области ануса и прямой кишки после введения суппозитория)

Headache, dizziness, diarrhea [5], hot sensation or flashes of heat, constipation, local reactions (burning at the injection site; burning sensation in the anus and rectum after the introduction of the suppository)

\begin{tabular}{lll}
\hline Палоносетрон & Противорвотное & Головная боль, головокружение [9] \\
(Palonosetronum) & Antiemetic & Headache, dizziness [9]
\end{tabular}

Palonosetron

(Palonosetronum)

Headache, dizziness [9]

Прукалоприд Слабительное

(Prucalopridum) Laxative

Prucalopride

(Prucalopridum)

Серотонин

(Serotoninum)

Serotonin

(Serotoninum)

Расстройства ЖКТ (тошнота, запор, диарея и боль в животе), головная боль, головокружение [7]

Gastrointestinal disorders (nausea, constipation, diarrhea and abdominal pain), headache, dizziness [7]

\section{Гемостатическое}

Hemostatic

Беспокойство/тревога, бессонница, ажитация/акатизия, сексуальная дисфункция, тошнота, спазмы ЖКТ, диарея, головная боль [11]. При быстром введении, а также при введении препарата, разведенного в малом объеме жидкости - боль по ходу вены, боли в животе, неприятные ощущения в области сердца, затруднение дыхания, снижение диуреза, повышение АД, тяжесть в голове

Nervousness/anxiety, insomnia, agitation/akathisia, sexual dysfunction, nausea, gastrointestinal spasms, diarrhea, headache [11]. With rapid infusion, as well as with the administration of a drug diluted in a small volume of fluid - pain along the vein, abdominal pain, discomfort in the region of the heart, breathing difficulties, diminished diuresis, high blood pressure, heaviness in the head

\begin{tabular}{ll}
\hline Суматриптан & Противомигренозное \\
(Sumatriptanum) & Anti-migraine \\
Sumatriptan &
\end{tabular}

(Sumatriptanum)

\begin{tabular}{ll}
\hline Tрописетрон & Противорвотное \\
(Tropisetronum) & Antiemetic
\end{tabular}

(Tropisetronum) Antiemetic

Tropisetron

(Tropisetronum)

Покалывание или онемение, ощущение теплоты, жара, жжения или холода, чувство тяжести, сдавления или стягивания головы, грудной клетки, шеи или других частей тела [6] Tingling or numbness, a feeling of warmth, heat, burning or cold, a feeling of heaviness, compression or contraction of the head, chest, neck or other body parts [6]

Головная боль, головокружение, диарея [5], при быстром введении, а также при введении препарата, разведенного в малом объеме жидкости - боль по ходу вены, боли в животе, неприятные ощущения в области сердца, повышение АД, тяжесть в голове, затруднение дыхания, тошнота, снижение диуреза Headache, dizziness, diarrhea [5], with rapid infusion, as well as with the administration of a drug diluted in a small volume of fluid - pain along the vein, abdominal pain, discomfort in the region of the heart, high blood pressure, heaviness in the head, breathing difficulties, nausea, diminished diuresis

\begin{tabular}{ll}
\hline $\begin{array}{l}\text { Элетриптан } \\
\text { (Eletriptanum) }\end{array}$ & Противомигренозное \\
Eletriptan & Anti-migraine
\end{tabular}

(Eletriptanum)
Фарингит и ринит, сонливость, головная боль, головокружение, ощущение покалывания или другие нарушения чувствительности, озноб, астения, симптомы со стороны грудной клетки (боль, чувство сжатия, давления), аллергические реакции, артериальная гипертензия, гипертонус мышц, гипестезия, миастения, вертиго, учащенное сердцебиение и тахикардия, ощущение стеснения в горле, боль в животе, тошнота, сухость во рту и диспепсия, повышенное потоотделение, боль в спине, боль в мышцах, ощущение тепла или приливы жара к лицу Pharyngitis and rhinitis, drowsiness, headache, dizziness, tingling or other dysesthesia, chilly sensation, asthenia, chest symptoms (pain, feeling of compression, pressure), allergic reactions, hypertension, muscle hypertonia, hypoesthesia, myasthenia gravis, vertigo, palpitations and tachycardia, tightness in the throat, abdominal pain, nausea, dry mouth and dyspepsia, hyperhidrosis, back pain, muscle pain, warm sensation or hot flashes to the face 
Таблица 3. Лекарственные препараты серотонинергических средств, зарегистрированные в Российской Федерации

Table 3. Drug products of serotonergic agents registered in the Russian Federation

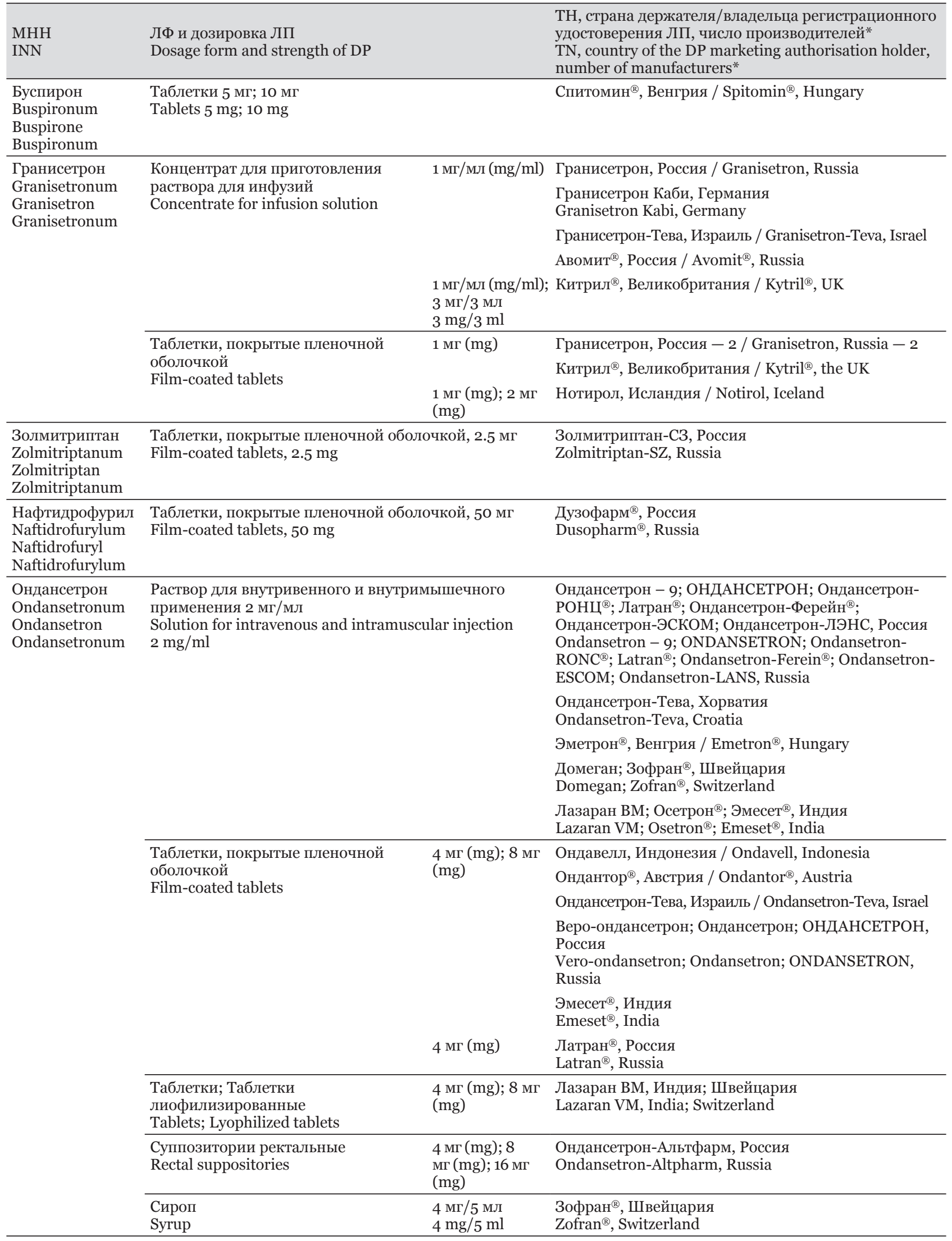




\begin{tabular}{|c|c|c|}
\hline $\begin{array}{l}\text { MHH } \\
\text { INN }\end{array}$ & $\begin{array}{l}\text { ЛФ и дозировка ЛП } \\
\text { Dosage form and strength of DP }\end{array}$ & $\begin{array}{l}\text { TH, страна держателя/владельца регистрационного } \\
\text { удостоверения ЛП, число производителей* } \\
\text { TN, country of the DP marketing authorization holder, } \\
\text { number of manufacturers* }\end{array}$ \\
\hline $\begin{array}{l}\text { Палоносетрон } \\
\text { Palonosetronum } \\
\text { Palonosetron } \\
\text { Palonosetronum }\end{array}$ & $\begin{array}{l}\text { Раствор для внутривенного введения о.25 мг/5 мл } \\
\text { Solution for intravenous injection } 0.25 \mathrm{mg} / 5 \mathrm{ml}\end{array}$ & $\begin{array}{l}\text { Оницит }{ }^{\circledR}, \text { Ирландия } \\
\text { Onicit }^{\circledR} \text {, Ireland }\end{array}$ \\
\hline $\begin{array}{l}\text { Прукалоприд } \\
\text { Prucalopridum } \\
\text { Prucalopride } \\
\text { Prucalopridum }\end{array}$ & $\begin{array}{l}\text { Таблетки, покрытые пленочной оболочкой, } 1 \text { мг; } 2 \text { мг } \\
\text { Film-coated tablets, } 1 \text { mg; } 2 \text { mg }\end{array}$ & $\begin{array}{l}\text { ВЕГАПРАТ }^{\circledR} ; \text { Резолор, Россия } \\
\text { VEGAPRAT }^{\circledR} \text {; Resolor, Russia }\end{array}$ \\
\hline $\begin{array}{l}\text { Серотонин } \\
\text { Serotoninum } \\
\text { Serotonin } \\
\text { Serotoninum }\end{array}$ & $\begin{array}{l}\text { Раствор для внутривенного и внутримышечного } \\
\text { применения 10 мг/мл } \\
\text { Solution for intravenous and intramuscular injection } 10 \\
\mathrm{mg} / \mathrm{ml}\end{array}$ & $\begin{array}{l}\text { CEРОТОНИНА АДИПИНАТ; Динатон }{ }^{\circledR}, \text { Россия } \\
\text { SEROTONIN ADIPATE; Dinaton }{ }^{\circledR}, \text { Russia }^{2}\end{array}$ \\
\hline \multirow[t]{6}{*}{$\begin{array}{l}\text { Суматриптан } \\
\text { Sumatriptanum } \\
\text { Sumatriptan } \\
\text { Sumatriptanum }\end{array}$} & \multirow[t]{4}{*}{$\begin{array}{l}\text { Таблетки, покрытые пленочной } \\
\text { оболочкой } \\
\text { Film-coated tablets }\end{array}$} & $\begin{array}{l}\text { Суматриптан - 4; Суматриптан Канон; Суматрип- } \\
\text { тан-OBL; Амигренин }{ }^{\circledR} ; \text { Имигран }{ }^{\circledR} \text {, Россия } \\
\text { Sumatriptan - 4; Sumatriptan Canon; Sumatriptan- } \\
\text { OBL; Amigrenin }^{\circledR} ; \text { Imigran }^{\circledR}, \text { Russia }\end{array}$ \\
\hline & & $\begin{array}{l}\text { Рапимед, Ирландия } \\
\text { Rapimed, Ireland }\end{array}$ \\
\hline & & $\begin{array}{l}\text { Сумамигрен }{ }^{\circledR}, \text { Польша } \\
\text { Sumamigrene }{ }^{\circledR} \text {, Poland }\end{array}$ \\
\hline & & $\begin{array}{l}\text { Суматриптан-Тева, Израиль } \\
\text { Sumatriptan-Teva, Israel }\end{array}$ \\
\hline & \multirow[t]{2}{*}{$\begin{array}{l}\text { Таблетки } \\
\text { Tablets }\end{array}$} & $\begin{array}{l}\text { Суматриптан, Индия } \\
\text { Sumatriptan, India }\end{array}$ \\
\hline & & $\begin{array}{l}\text { Суматриптан Адифарм, Болгария } \\
\text { Sumatriptan Adipharm, Bulgaria }\end{array}$ \\
\hline \multirow{2}{*}{$\begin{array}{l}\text { Tрописетрон } \\
\text { Tropisetronum } \\
\text { Tropisetron } \\
\text { Tropisetronum }\end{array}$} & $\begin{array}{l}\text { Раствор для внутривенного введения } 1 \mathrm{мг} / \text { мл } \\
\text { Solution for intravenous injection } 1 \mathrm{mg} / \mathrm{ml}\end{array}$ & $\begin{array}{l}\text { Тропиндол }{ }^{\circledR}, \text { Россия } \\
\text { Tropindol }^{\circledR} \text {, Russia }\end{array}$ \\
\hline & $\begin{array}{l}\text { Капсулы } 5 \text { мг } \\
\text { Capsules, } 5 \mathrm{mg}\end{array}$ & $\begin{array}{l}\text { Тропиндол }{ }^{\circledR}, \text { Россия } \\
\text { Tropindol }{ }^{\circledR} \text {, Russia }\end{array}$ \\
\hline $\begin{array}{l}\text { Элетриптан } \\
\text { Eletriptanum } \\
\text { Eletriptan } \\
\text { Eletriptanum }\end{array}$ & $\begin{array}{l}\text { Таблетки, покрытые пленочной } \\
\text { мг } \\
\text { Film-coated tablets, } 20 \mathrm{mg} ; 40 \mathrm{mg}\end{array}$ & $\begin{array}{l}\text { Релпакс }{ }^{\circledR}, \text { CШA } \\
\text { Relpax }^{\circledR} \text {, USA }\end{array}$ \\
\hline
\end{tabular}

* Число производителей, выпускающих ЛП под данным ТН, показывает цифра, стоящая через тире после названия страны. Цифра указывает только несколько производителей; если цифры нет - значит данный ЛП под этим ТН выпускает только один производитель. * The number of manufacturers that produce DP under this TN is shown by the number that is separated by a dash from the country name. The number indicates only a few manufacturers; if there is no number, then this particular DP under this TN is produced by only one manufacturer.

CYP3A4, CYP1A2, CYP2D6 и других микросомальных ферментов печени, а также с барбитуратами и трициклическими антидепрессантами вследствие изменения уровня агониста серотониновых рецепторов в плазме крови и его фармакологических эффектов [4].

Основные характеристики фармакологического действия и побочных эффектов серотонинергических ЛП представлены в табл. 2.

В настоящее время в Государственном реестре лекарственных средств России [4] зарегистрированы 11 международных непатентованных наименований ЛП серотонинергических средств под 70 торговыми наименованиями (ТН) в различных ЛФ (табл. 3).
State Register of Medicinal Remedies of Russia [4] (Table 3).

Analysis of the range of serotonergic DP showed that the domestic pharmaceutical market is dominated by film-coated tablets $-41.43 \%$, as well as solution for intravenous and intramuscular use $34.28 \%$. In addition, the pharmaceutical market presents DP in the form of: concentrate for infusions $-8.57 \%$, tablets $-5.71 \%$, solution for intravenous injection $-2.86 \%$, rectal suppositories $2.86 \%$, syrup $-1.43 \%$, lyophilized tablets $-1.43 \%$ and capsules $-1.43 \%$.

Currently, only one DP (ondansetron) is included in the List of Vital and Essential Drugs in the form of syrup, rectal suppositories, tablets (inclu- 


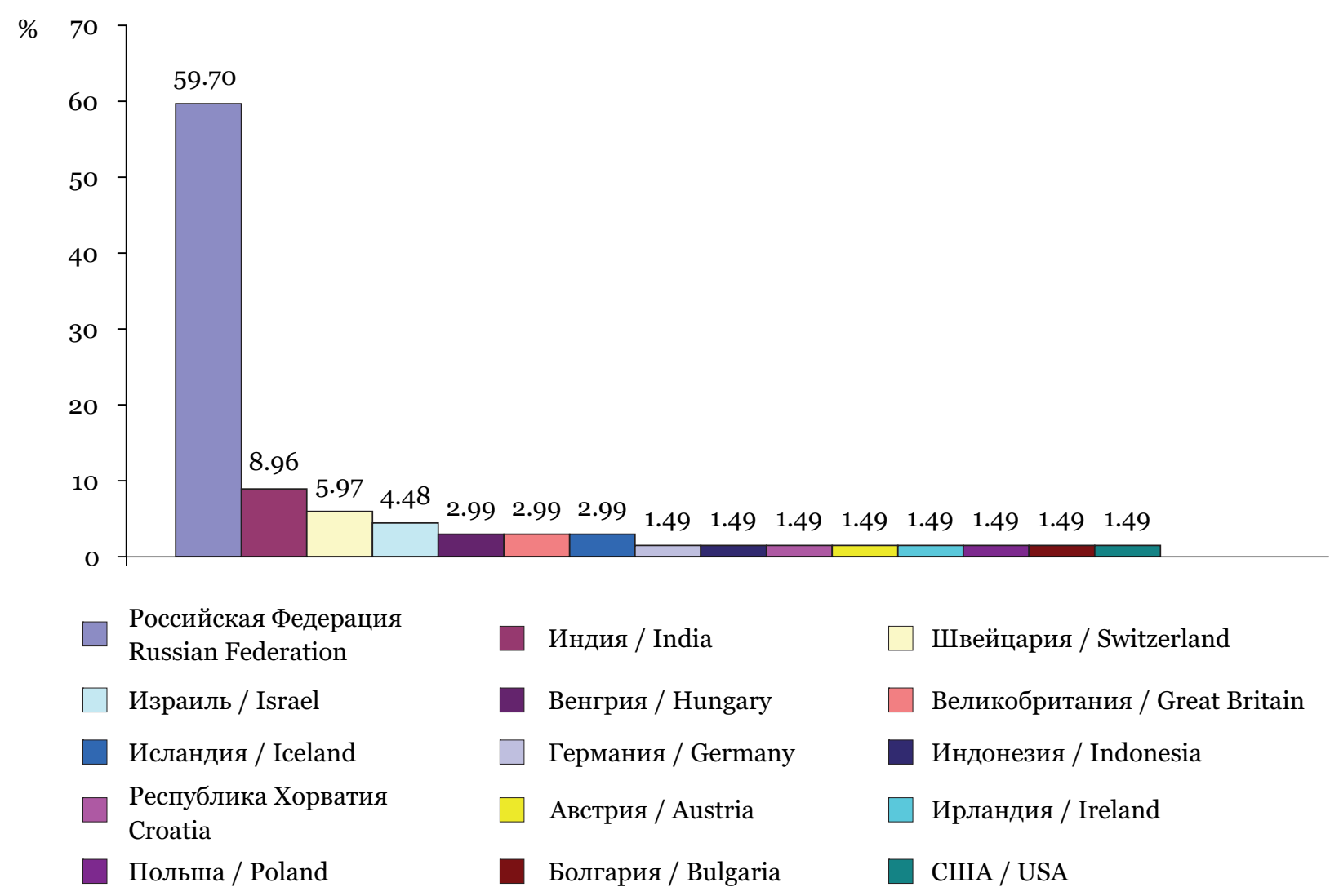

Рис. 1. Держатели/владельцы регистрационного удостоверения на ЛП серотонинергических средств в России Fig. 1. Holders of marketing authorization for serotonergic DP in Russia

Анализ ассортимента ЛФ серотонинергических ЛП показал, что на отечественном фармацевтическом рынке преобладают таблетки, покрытые пленочной оболочкой $-41.43 \%$, а также инъекционный раствор для внутривенного и внутримышечного применения - 34.28 \%. Кроме того, на фармацевтическом рынке представлены ЛП в виде: концентрата для приготовления раствора для инфузий $-8.57 \%$, таблеток $-5.71 \%$, раствора для внутривенного введения $-2.86 \%$, суппозиториев ректальных - $2.86 \%$, сиропа $1.43 \%$, таблеток лиофилизированных $-1.43 \%$ и капсул $-1.43 \%$.

В настоящее время лишь один ЛП (ондансетрон) вошел в перечень жизненно необходимых и важнейших ЛП в виде сиропа, суппозиториев ректальных, таблеток (в том числе лиофилизированных и покрытых пленочной оболочкой) [12], однако инъекционный раствор ондансетрона не включен в данный Перечень.

Большая часть зарегистрированных ТН приходится на долю отечественных предприятий, производящих воспроизведенные ЛП - $59.70 \%$. Зарубежные производители серотонинергических ЛП занимают 40.30 \% российского фарма- ding lyophilized and film-coated) [12], but the injection solution of ondansetron is not included in this List.

Most of the registered TN accounts for the domestic enterprises that produce generic DP $59.70 \%$. Foreign manufacturers of serotonergic DP occupy $40.30 \%$ of the Russian pharmaceutical market, with the leading positions belonging to manufacturers of India (8.96\%), Switzerland (5.97\%), Israel (4.48\%); $2.99 \%$ are divided by Hungary, Great Britain, Iceland and $1.49 \%$ - Germany, Indonesia, Croatia, Austria, Ireland, Poland, Bulgaria, the United States (Fig. 1).

The range of pharmaceutical substances for the production of serotonergic DP is shown in Table 4.

The pharmaceutical substances buspirone and eletriptan are not currently registered in Russia.

The Russian pharmaceutical market is dominated by foreign manufacturers of serotonergic substances $-52.38 \%$. Indian manufacturers lead the way $(28.57 \%)$, followed by China $(19.05 \%)$ and Spain (4.76\%). The proportion of domestic provi- 
Таблица 4. Фармацевтические субстанции для производства серотонинергических средств, зарегистрированные в России

Table 4. Pharmaceutical substances for the production of serotonergic DP registered in Russia

\begin{tabular}{|c|c|c|c|}
\hline $\begin{array}{l}\text { МНН или группи- } \\
\text { рованное (химиче- } \\
\text { ское) название } \\
\text { INN or generic } \\
\text { (chemical) name }\end{array}$ & $\begin{array}{l}\text { Наименование фармацев- } \\
\text { тической субстанции } \\
\text { Pharmaceutical substance name }\end{array}$ & $\begin{array}{l}\text { Производитель } \\
\text { Manufacturer }\end{array}$ & $\begin{array}{l}\text { Страна } \\
\text { Country }\end{array}$ \\
\hline \multirow[t]{4}{*}{$\begin{array}{l}\text { Гранисетрон } \\
\text { Granisetron }\end{array}$} & $\begin{array}{l}\text { Гранисетрона гидрохлорид } \\
\text { Granisetron hydrochloride }\end{array}$ & $\begin{array}{l}\text { Ухань Биокоз Фармасьютикал Девелопмент Ко. Лтд } \\
\text { Wuhan Biocause Pharmaceutical Development Co., Ltd }\end{array}$ & $\begin{array}{l}\text { Китай } \\
\text { China }\end{array}$ \\
\hline & & $\begin{array}{l}\text { Цилу Фармасьютикал Ко. Лтд. } \\
\text { Qilu Pharmaceutical Co., Ltd }\end{array}$ & $\begin{array}{l}\text { Китай } \\
\text { China }\end{array}$ \\
\hline & & $\begin{array}{l}\text { OОО «Технология лекарств» } \\
\text { Technology of Medicines LLC }\end{array}$ & $\begin{array}{l}\text { Россия } \\
\text { Russia }\end{array}$ \\
\hline & & $\begin{array}{l}\text { ЗАО «Биокад» } \\
\text { Biocad CJSC }\end{array}$ & $\begin{array}{l}\text { Россия } \\
\text { Russia }\end{array}$ \\
\hline $\begin{array}{l}\text { Золмитриптан } \\
\text { Zolmitriptan }\end{array}$ & $\begin{array}{l}\text { Золмитриптан } \\
\text { Zolmitriptan }\end{array}$ & $\begin{array}{l}\text { CMC Фармацеутикалс Лтд } \\
\text { SMS Pharmaceuticals Ltd }\end{array}$ & $\begin{array}{l}\text { Индия } \\
\text { India }\end{array}$ \\
\hline $\begin{array}{l}\text { Нафтидрофурил } \\
\text { Naftidrofuryl }\end{array}$ & $\begin{array}{l}\text { Нафтидрофурил } \\
\text { Naftidrofuryl }\end{array}$ & ООО «БЕРАХИМ» / Berahim LLC & $\begin{array}{l}\text { Россия } \\
\text { Russia }\end{array}$ \\
\hline \multirow[t]{5}{*}{$\begin{array}{l}\text { Ондансетрон } \\
\text { Ondansetron }\end{array}$} & $\begin{array}{l}\text { Ондансетрона гидрохлорида } \\
\text { дигидрат } \\
\text { Ondansetron hydrochloride } \\
\text { dihydrate }\end{array}$ & $\begin{array}{l}\text { ФГБУ «НМИЦ онкологии им. Н.Н. Блохина» } \\
\text { Минздрава России } \\
\text { NN Blokhin National Medical Research Center } \\
\text { of Oncology }\end{array}$ & $\begin{array}{l}\text { Poсcия } \\
\text { Russia }\end{array}$ \\
\hline & & $\begin{array}{l}\text { ФГУП НПЦ «Фармзащита» ФМБА России } \\
\text { Scientific and Production Center "Farmzashchita” }\end{array}$ & $\begin{array}{l}\text { Россия } \\
\text { Russia }\end{array}$ \\
\hline & $\begin{array}{l}\text { Ондансетрона гидрохлорид-Лонг } \\
\text { ШенгФарма Лимитед } \\
\text { Ondansetron Hydrochloride-Long } \\
\text { Sheng Pharma Limited }^{\circledR} \\
\end{array}$ & $\begin{array}{l}\text { Цилу Фармасьютикал Ко. Лтд. } \\
\text { Qilu Pharmaceutical Co., Ltd }\end{array}$ & $\begin{array}{l}\text { Китай } \\
\text { China }\end{array}$ \\
\hline & $\begin{array}{l}\text { Ондансетрона гидрохлорид } \\
\text { Ondansetron hydrochloride }\end{array}$ & $\begin{array}{l}\text { Сан Фармасьютикал Индастриз Лтд } \\
\text { Sun Pharmaceutical Industries Ltd }\end{array}$ & $\begin{array}{l}\text { Индия } \\
\text { India }\end{array}$ \\
\hline & & $\begin{array}{l}\text { Кадила Фармасьютикалз Лимитед } \\
\text { Cadila Pharmaceuticals Limited }\end{array}$ & $\begin{array}{l}\text { Индия } \\
\text { India }\end{array}$ \\
\hline $\begin{array}{l}\text { Палоносетрон } \\
\text { Palonosetron }\end{array}$ & $\begin{array}{l}\text { Палоносетрона гидрохлорид } \\
\text { Palonosetron hydrochloride }\end{array}$ & $\begin{array}{l}\text { ФГУП «ГосЗМП» } \\
\text { State Plant of Medical Preparations }\end{array}$ & $\begin{array}{l}\text { Россия } \\
\text { Russia }\end{array}$ \\
\hline $\begin{array}{l}\text { Прукалоприд } \\
\text { Prucalopride }\end{array}$ & $\begin{array}{l}\text { Прукалоприда сукцинат } \\
\text { Prucalopride succinate }\end{array}$ & $\begin{array}{l}\text { ЗАО «Обнинская химико-фармацевтическая } \\
\text { компания» } \\
\text { Obninsk Chemical and Pharmaceutical Company CJSC }\end{array}$ & $\begin{array}{l}\text { Россия } \\
\text { Russia }\end{array}$ \\
\hline $\begin{array}{l}\text { Серотонин } \\
\text { Serotonin }\end{array}$ & $\begin{array}{l}\text { Серотонина адипинат } \\
\text { Serotonin adipinate }\end{array}$ & $\begin{array}{l}\text { ФГУП НПЦ «Фармзащита» ФМБА России } \\
\text { Scientific and Production Center "Farmzashchita" }\end{array}$ & $\begin{array}{l}\text { Poсcия } \\
\text { Russia } \\
\end{array}$ \\
\hline \multirow[t]{4}{*}{$\begin{array}{l}\text { Суматриптан } \\
\text { Sumatriptan }\end{array}$} & $\begin{array}{l}\text { Суматриптана сукцинат } \\
\text { Sumatriptana succinate }\end{array}$ & $\begin{array}{l}\text { Нош Лабз Прайвет Лимитед } \\
\text { Nosch Labs Private Limited }\end{array}$ & $\begin{array}{l}\text { Индия } \\
\text { India }\end{array}$ \\
\hline & & $\begin{array}{l}\text { Вамси Лабс Лтд } \\
\text { Vamsi Labs Ltd }\end{array}$ & $\begin{array}{l}\text { Индия } \\
\text { India }\end{array}$ \\
\hline & & $\begin{array}{l}\text { CMC Фармацеутикалс Лтд. } \\
\text { SMS Pharmaceuticals Ltd }\end{array}$ & $\begin{array}{l}\text { Индия } \\
\text { India }\end{array}$ \\
\hline & & $\begin{array}{l}\text { Кимика Синтетика C.A. } \\
\text { Quimica Sintetica S.A. }\end{array}$ & $\begin{array}{l}\text { Испания } \\
\text { Spain }\end{array}$ \\
\hline \multirow[t]{2}{*}{$\begin{array}{l}\text { Трописетрон } \\
\text { Tropisetron }\end{array}$} & $\begin{array}{l}\text { Трописетрона гидрохлорид } \\
\text { Tropisetron hydrochloride }\end{array}$ & $\begin{array}{l}\text { Цилу Фармасьютикал Ко. Лтд. } \\
\text { Qilu Pharmaceutical Co., Ltd }\end{array}$ & $\begin{array}{l}\text { Китай } \\
\text { China }\end{array}$ \\
\hline & & $\begin{array}{l}\text { ОАО «ЦХЛС-ВНИХФИ» } \\
\text { Center for the Chemistry of Medicinal Products OJSС }\end{array}$ & $\begin{array}{l}\text { Россия } \\
\text { Russia }\end{array}$ \\
\hline
\end{tabular}

цевтического рынка, причем лидирующие позиции принадлежат производителям Индии (8.96 \%), Швейцарии (5.97\%), Израиля (4.48 \%); по 2.99 \% делят Венгрия, Великобритания, Исландия и по 1.49 \% - Германия, Индонезия, Республика Хорватия, Австрия, Ирландия, Польша, Болгария, США (рис. 1). ders accounts for $47.62 \%$ of manufacturers of serotonergic substances registered in Russia, and this indicates the growing potential of domestic pharmaceutical enterprises. Pharmaceutical substances produced in India, China and Spain are also registered (Fig. 2). 
$\%$

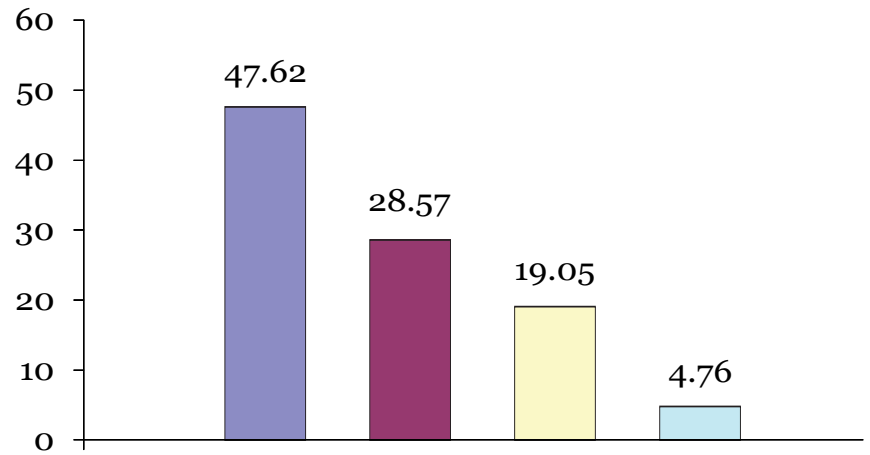

Российская Федерация

Russian Federation

Индия / India

Китай / China

Испания / Spain

Рис. 2. Производители субстанций серотонинергических средств, зарегистрированных в России

Fig. 2. Manufacturers of serotonergic substances registered in Russia

Ассортимент фармацевтических субстанций для производства серотонинергических ЛП приведен в табл. 4.

Фармацевтические субстанции буспирон и элетриптан в России в настоящее время не зарегистрированы.

На российском фармацевтическом рынке преобладают зарубежные производители субстанций серотонинергических средств $52.38 \%$. Лидируют индийские производители (28.57 \%), за ними следуют Китай (19.05 \%) и Испания (4.76 \%). На долю отечественных поставщиков приходится 47.62 \% производителей субстанций серотонинергических средств, зарегистрированных в России, и это свидетельствует о растущем потенциале отечественных фармацевтических предприятий. Также зарегистрированы фармацевтические субстанции производства Индии, Китая и Испании (рис. 2).

\section{ЗАКЛЮЧЕНИЕ}

Проведенное исследование позволяет сделать следующие выводы:

1. В Государственном реестре лекарственных средств России зарегистрировано 11 МНН ЛП серотонинергических средств под 70 торговыми наименованиями.

2. Серотонинергические ЛП зарегистрированы в России в виде ЛФ: таблетки - 5.71 \%; таблетки, покрытые пленочной оболочкой $-41.43 \%$; инъекционные растворы (растворы для внутривенного и внутримышечного применения $34.28 \%$; растворы для внутривенного введения 2.86 \%); концентрат для приготовления раствора для инфузий $-8.57 \%$; суппозитории ректальные - 2.86 \%; сироп, таблетки лиофилизированные и капсулы - по $1.43 \%$.

3. Лидирующая роль на отечественном фармацевтическом рынке ЛП серотонинергических

\section{CONCLUSION}

The study allows us to draw the following conclusions:

1. The State Register of Medicinal Remedies of Russia has registered 11 INN serotonergic agents' DP under 70 trade names.

2. Serotonergic DP are registered in Russia in the following dosage forms: tablets $-5.71 \%$; filmcoated tablets $-41.43 \%$; solutions for injection (solutions for intravenous and intramuscular use $34.28 \%$; solutions for intravenous injection $2.86 \%$ ); concentrate for infusion solutions $-8.57 \%$; rectal suppositories $-2.86 \%$; syrup, lyophilized tablets and capsules - by $1.43 \%$.

3 . The leading role in the domestic pharmaceutical market of serotonergic agents' DP belongs to domestic enterprises (59.70\%). The remaining 40.30\% belongs to foreign manufacturers: $8.96 \%$ - India, $5.97 \%$ - Switzerland, 4.48\% - Israel, 2.99\% - Hungary, Great Britain, Iceland and 1.49\% - Germany, Indonesia, the Republic of Croatia, Austria, Ireland, Poland, Bulgaria, the United States.

4. Analysis of the range of pharmaceutical substances for the production of serotonergic agents showed that the Russian pharmaceutical market is significantly dominated by substances of foreign production (52.38\%). The proportion of pharmaceutical substances of domestic production registered in Russia accounts for $47.62 \%$.

5. Currently, there are no DF of serotonergic agents of domestic production in the pharmaceutical market of the Russian Federation: buspirone (tablets), ondansetron (tablets and lyophilized ones), palonosetron (solution for intravenous injection), sumatriptan (tablets) and eletriptan (film-coated tablets), which makes their pharmaceutical development relevant.

Conflict of interest. The authors declare no conflict of interest. 
средств принадлежит отечественным предприятиям (59.70 \%). Остальные 40.30 \% принадлежит зарубежным производителям: $8.96 \%$ - Индии, $5.97 \%$ - Швейцарии, $4.48 \%$ - Израилю, по $2.99 \%$ - Венгрии, Великобритании, Исландии и по 1.49 \% - Германии, Индонезии, Республике Хорватии, Австрии, Ирландии, Польше, Болгарии, США.

4. Анализ ассортимента фармацевтических субстанций для производства серотонинергических средств показал, что на российском фармацевтическом рынке значительно преобладают субстанции зарубежного производства (52.38 \%). На долю фармацевтических субстанций отече-

\section{СПИСОК ЛИТЕРАТУРЫ}

1. Mathew N.T., Hettiarachchi J., Alderman J. Tolerability and safety of eletriptan in the treatment of migraine: a comprehensive review // Headache. 2003. Vol. 43 (9). P. 962-974. doi: 10.1046/j.1526-4610.2003.03188.x.

2. Бохан Н.А., Иванова С.А., Левчук Л.А. Серотониновая система в модуляции депрессивного и агрессивного поведения. Томск: Иван Фёдоров, 2013. 102 с.

3. Левин О.С. Применение буспирона в клинической практике // Журн. неврологии и психиатрии им. C.C. Корсакова. 2015. Т. 115, № 4. С. 83-87. doi: 10.17116/jnevro20151154183-87.

4. Государственный реестр лекарственных средств. URL: http://www.grls.rosminzdrav.ru. Дата обращения: 19.10.2020.

5. Abali H., Celik I. Tropisetron, ondansetron, and granisetron for control of chemotherapy-induced emesis in Turkish cancer patients: a comparison of efficacy, side-effect profile, and cost // Cancer Invest. 2007. Vol. 25 (3). P. 135-139. doi: 10.1080/07357900701208709.

6. Mathew N.T. Serotonin $1 \mathrm{D}(5-\mathrm{HT} 1 \mathrm{D})$ agonists and other agents in acute migraine // Neurol. Clin. 1997. Vol. 15 (1). P. 61-83. doi: 10.1016/so733-8619(05)70295-4.

7. Camilleri M., Piessevaux H., Yiannakou Y. et al. Efficacy and safety of prucalopride in chronic constipation: an integrated analysis of six randomized, controlled clinical trials // Dig. Dis. Sci. 2016. Vol. 61 (8). P. 2357-2372. doi: 10.1007/s10620-016-4147-9.

8. Lu D., Song H., Hao Z., Wu T., McCleery J. Naftidrofuryl for dementia // Cochrane Database Syst. Rev. 2011. Vol. 12: CDoo2955.

9. Bhattacharjee D.P., Dawn S., Nayak S. et al. A comparative study between palonosetron and granisetron to prevent postoperative nausea and vomiting after laparoscopic cholecystectomy // J. Anaesthesiol. Clin. Pharmacol. 2010. Vol. 26 (4). P. 480-483.

10. Tfelt-Hansen P. Acute pharmacotherapy of migraine, tension-type headache, and cluster headache // J. Headache Pain. 2007. Vol. 8. P. 127-134.

11. Stahl S.M. Mechanism of action of serotonin selective reuptake inhibitors: Serotonin receptors and pathways mediate therapeutic effects and side effects // J. Affect. Disord. 1998. Vol. 51 (3). P. 215-235. doi: 10.1016/ So165-0327(98)o0221-3. ственного производства, зарегистрированных в России, приходится $47.62 \%$.

5. На данный момент на фармацевтическом рынке РФ отсутствуют ЛФ серотонинергических средств отечественного производства: буспирон (таблетки), ондансетрон (таблетки и таблетки лиофилизированные), палоносетрон (раствор для внутривенного введения), суматриптан (таблетки) и элетриптан (таблетки, покрытые пленочной оболочкой), что делает актуальной их фармацевтическую разработку.

Конфликт интересов. Авторы заявляют об отсутствии конфликта интересов.

\section{REFERENCES}

1. Mathew N.T., Hettiarachchi J., Alderman J. (2003). Tolerability and safety of eletriptan in the treatment of migraine: a comprehensive review. Headache, 43 (9), 962-974. doi: 10.1046/j.1526-4610.2003.03188.x.

2. Bokhan N.A., Ivanova S., Levchuk L.A. (2013). Serotonin System in Modulation of Depressive and Addictive Behavior. Tomsk: Ivan Fedorov Publ., 102 p. In Russ.

3. Levin O.S. (2015). The use of buspirone in clinical practice. Korsakov's Journal of Neurology and Psychiatry, 115, 4, 83-87. doi: 10.17116/jnevro20151154183-87.

4. State Register of Medicinal Remedies. Retrieved on October 19, 2020 from http://www.grls.rosminzdrav.ru. In Russ.

5. Abali H., Celik I. (2007). Tropisetron, ondansetron, and granisetron for control of chemotherapy-induced emesis in Turkish cancer patients: a comparison of efficacy, side-effect profile, and cost. Cancer Invest., 25 (3), 135-139. doi: 10.1080/07357900701208709.

6. Mathew N.T. (1997). Serotonin 1D (5-HT1D) agonists and other agents in acute migraine. Neurol. Clin., 15 (1), 61-83. doi: 10.1016/so733-8619(05)70295-4.

7. Camilleri M., Piessevaux H., Yiannakou Y. et al. (2016). Efficacy and safety of prucalopride in chronic constipation: an integrated analysis of six randomized, controlled clinical trials. Dig. Dis. Sci., 61 (8), 23572372. doi: 10.1007/s10620-016-4147-9.

8. Lu D., Song H., Hao Z., Wu T., McCleery J. (2011). Naftidrofuryl for dementia. Cochrane Database Syst. Rev., 12, CDoo2955.

9. Bhattacharjee D.P., Dawn S., Nayak S. et al. (2010). A comparative study between palonosetron and granisetron to prevent postoperative nausea and vomiting after laparoscopic cholecystectomy. J. Anaesthesiol. Clin. Pharmacol., 26 (4), 480-483.

10. Tfelt-Hansen P. (2007). Acute pharmacotherapy of migraine, tension-type headache, and cluster headache. J. Headache Pain, 8, 127-134.

11. Stahl S.M. (1998). Mechanism of action of serotonin selective reuptake inhibitors: Serotonin receptors and pathways mediate therapeutic effects and side effects. J. Affect. Disord., 51 (3), 215-235. doi: 10.1016/So1650327(98)00221-3. 
12. Об утверждении перечня жизненно необходимых и важнейших лекарственных препаратов на 2020 год, а также перечней лекарственных препаратов для медицинского применения и минимального ассортимента лекарственных препаратов, необходимых для оказания медицинской помощи: Распоряжение Правительства РФ от 12.10.2019 N 2406-р (ред. от 12.10.2020). URL: https://normativ.kontur. $\mathrm{ru} /$ document? moduleId=1\&documentId=360864. Дата обращения: 23.10.2020.

\section{СВЕДЕНИЯ ОБ АВТОРАХ}

Нягматуллина Виктория Рафаэльевна инженер-технолог 1-й категории технологической лаборатории исследовательского отдела АО «Татхимфармпрепараты» (Казань).

Егорова Светлана Николаевна - д-р фармацевт. наук, профессор, заместитель директора по образовательной деятельности Института фармации ФГБОУ ВО «Казанский государственный медицинский университет» Минздрава России.

Чувашова Динара Петровна - канд. фармацевт. наук, начальник технологической лаборатории исследовательского отдела АО «Татхимфармпрепараты» (Казань).

Филиппов Юрий Валерьевич - канд. хим. наук, начальник исследовательского отдела АО «Татхимфармпрепараты» (Казань).

О бразец ци ти рования : Нягматуллина B.P., Егорова С.Н., Чувашова Д.П., Филиппов Ю.В. Комплексный анализ ассортимента серотонинергических средств и субстанций для их производства, зарегистрированных в России // Journal of Siberian Medical Sciences. 2021. № 2. C. 37-48.
12. On a confirmation of the List of Vital and Essential DP for 2020, as well as the Lists of DP for Medical Use and the Required Drugs for the Delivering of Health Care: The Order No. 2406-r of the Russian Federation Government of October 12, 2019 (as amended on 12.10.2020). Retrieved on October 23, 2020 from https://normativ.kontur.ru/document?moduleId=1\& documentId $=360864$.

\section{ABOUT THE AUTHORS}

Niagmatullina Viktoriya Rafaelevna - the $1^{\text {st }}$ Category Process Engineer, Technological Laboratory, Department of Research, JSC "Tatchempharmpreparaty" (Kazan).

Egorova Svetlana Nikolaevna - Dr. Sci. (Pharmaceut.), Professor, Deputy Director for Educational Activities, Institute of Pharmacy, Kazan State Medical University.

Chuvashova Dinara Petrovna - Cand. Sci. (Pharmaceut.), Head, Technological Laboratory, Department of Research, JSC "Tatchempharmpreparaty" (Kazan).

Filippov Yuriy Valerievich - Cand. Sci. (Chem.), Head, Department of Research, JSC “Tatchempharmpreparaty" (Kazan).

Citation example: Niagmatullina V.R., Egorova S.N., Chuvashova D.P., Filippov Yu.V. (2021). Comprehensive analysis of the range of serotonergic agents and substances for their production registered in Russia. Journal of Siberian Medical Sciences, 2, 37-48. 